\title{
CORRESPONDENCE
}

\section{HERCYNIAN Fe-Mg METASOMATISM IN CORNWALL}

SIR,--Knowing something of Miss Reynolds's views on petrogenesis from her previous essays on this subject, I am not at all surprised to find the disagreement she records (Geol. Mag., 1947, pp. 33-50) with Flett and Tilley's derivation of the greenstone and cummingtonitebearing hornfelses of the Kenidjack-Botallack area, Cornwall. Rocks long recognized as greenstones derived by thermal metamorphism of sheared basic igneous rocks, and mapped as such by the Geological Survey, are now reinterpreted by her as altered limestones; and the cummingtonite-anthophyllite assemblages intimately associated with the greenstones and regarded as their derivatives are classed as altered calcareous shales, desilicated and "basified ", if I am not mistaken, by action of an iron front of regional character which penetrated them and the associated " limestones" prior to the emplacement of the Land's End granite.

I may say at once that it is difficult to believe, on reading her contribution, that Miss Reynolds has found real opportunity to acquaint herself at first hand with the rocks she attempts to reinterpret ; conjuring, with von Wolff diagrams, ill suited for the purpose, provides, it seems, the real enlightenment, here as elsewhere. Nevertheless a critical field study taken in time might perhaps have saved her from this strange and fanciful version of the Cornish geological record.

I do not propose to dwell further on so gross an errorit may well be left to seek its own level in the heavy score of misinterpretations already standing to the credit of " front" petrology.

\section{E. Tilley.}

Department of Mineralogy and Petrology,

THE UNIVERSITY, CAMBridge. 10th February, 1947.

\section{CRYSTALLIZATION OF PLUTONIC AND HYPABYSSAL ROCKS}

SIR,-May I make the following reply to Dr. Nockolds's letter published in the last number of the Geological Magazine?

(1) In his paper Dr. Nockolds stated that discontinuous reaction "cannot happen in a eutectic system". He now claims to have meant no more than that a discontinuous reaction point is not a eutectic point. Why then cite Dr. Bowen in order to support a thing so selfevident ? What he did write was bound to lead the reader to assume that it was for systems with one or more eutectics that he used the term " eutectic system". 
(2) After two phases have begun to crystallize together, disappearance of one of these by reaction with the liquid necessitates simultaneous precipitation of a new phase. The number of crystalline phases may increase, bút cannot diminish, in a cooling system. What is asked of Dr. Nockolds is an explanation, not of incongruent melting, which is indeed familiar to every petrologist, but of the successive reductions in the number of phases during the periods between the crystallization of (i) olivine and augite, (ii) rhombic pyroxene and hornblende, and (iii) augite and biotite; how can two phases which crystallize together at one temperature become a reaction pair at a lower temperature ? Unless assertion constitutes proof, the statement in Dr. Nockolds's reply that the phase-boundary curve might be divided "into two parts, one of reaction, and one of simultaneous crystallization " is not an explanation.

$(3,4$, and 5). As the eutectic of " the imaginary polydimensional space diagram " is approached and the ferromagnesian minerals cease " to all intents and purposes " to crystallize, so the amount of residual liquid becomes, " to all intents and purposes", zero. It is mechanically impossible for such a small amount of liquid to be separated from the crystal aggregate without the fracturing of crystals throughout a large volume. What evidence does Dr. Nockolds have that such wholesale crushing has taken place in the Caledonian plutonic complexes ?

Dr. Nockolds has stated $(1940$, p. 503$)$ that with complete separation of the most basic material which could reasonably be assumed to have crystallized early, i.e. with complete fractionation, " the parent magma chosen is capable of yielding approximately 30 per cent of normal granodiorite" (my italics). We are now told (1946, p. 215), and the point is emphasized (1947, p. 60), that the degree of fractionation was " not particularly strong ". "A moderate but not particularly strong degree of fractionation" is only a qualitative statement, but it indicates that the process of crystal differentiation, in which Dr. Nockolds believes, is unlikely to produce more than 10-15 per cent of granodiorite and to separate even this amount, the crystal aggregate must be crushed. Associated with large bodies of granite one would therefore expect truly gigantic masses of basic rocks. Where are these ?

In the discussion on Dr. Nockolds's Garabal Hill paper, Dr. J. Phemister pointed out $(1940$, p. 510$)$ that " as a matter of fact, over 80 per cent of granodiorite was visible in the Garabal Hill complex, and, taken generally, the percentage must be still higher for the whole series of Lower Old Red intrusions ". Although never having replied to that criticism directly, Dr. Nockolds has warned us $(1940$, p. 503) of "the danger of drawing conclusions about the relative abundance of rock types from their present outcrops ", but he admits that "even so, there can be little doubt that granodiorite is relatively abundant ", 
i.e. relative to the basic rocks. Now, this problem is of the utmost importance in the evaluation of the hypothesis of crystal differentiation. At the present surface of the earth plutonic rocks are exposed which originated at various depths, and granitic rocks are found to be relatively and even increasingly abundant in the deepest exposures. We must assume, then, that Dr. Nockolds believes that the main bodies of basic crystal accumulates, even those corresponding to granites of relatively shallow depths, lie deeper than any level yet exposed by denudation. Has Dr. Nockolds formed an estimate of the depth in miles through which these basic crystals have sunk, or of the time between the initiation of crystallization at a high level in the earth, the settling out of the basic crystals (taking into account the enormous increase in viscosity at those great depths), and the first eruption of crystal accumulate back again to the upper part of the earth's crust ? If the Caledonian plutonic rocks owe their origin to this process, one is tempted to inquire whether 3,350 million years is not a conservative estimate of the age of the earth !

The analogy of "stones" sinking to the bottom of the magma chamber is inapt. Supporters of crystal differentiation have never explained how less dense rocks detached from the roof can sink through an alleged pyroxene-mica-diorite magma. That such rocks could sink through intruding crystal aggregates (cf. 7) with still higher density and viscosity seems even more improbable. It is the sinking of " corks" not of "stones" in which we are asked to believe.

It should be pointed out that four component phase diagrams should consist of separate tetrahedra for each temperature and for each pressure. If four component systems, requiring five dimensions, are compressed into three dimensions and then projected on to two, as Dr. Nockolds has done, they surely necessitate some word of explanation and justification for the benefit of readers who were assumed to be familiar only "with the more elementary types of phase diagram ".

(6) It is interesting to observe that in Dr. Nockolds's paper on "The Granitic Cotectic Curve", published in the last number of the Geological Magazine, he appears to be forced to call on "potash metasomatism" and "albitization" to account for certain of the aplites with which he treats. Does Dr. Nockolds believe that such $\mathrm{K}$ and $\mathrm{Na}$ migrations are examples of solid diffusion ?

(7) If the basic roof rocks were formed by the sinking of the early and heavy crystals to the bottom of the magma chamber, and the subsequent intrusion of the crystal aggregate through the overlying liquid and into the solid country rocks above, then explanations are required for (i) the postulate that, when the "squeeze" acted on the system and caused intrusion, the solid and not the available liquid was mobilized, (ii) the implication that the "squeezes" acted on each 
Caledonian plutonic mass at the same stages in their crystallization sequences, and (iii) the mechanics of intrusion of a crystal aggregate, e.g. by stoping or salt-dome mechanism, etc., and not forgetting the space problem.

The paucity of references in the literature suggests that many petrologists have overlooked the remarkable statements made by Dr. Nockolds (1940, pp. 504-5) on this subject : "In the early stages of differentiation, the crystals are literally abstracted from the liquid. ... The intrusion of . . . crystals with little or no magma gives rise to those types whose composition is believed to be governed ... by crystal accumulation. In the later stages of differentiation, however, the amount of crystalline material in the magma reservoir becomes much greater and finally exceeds the liquid in quantity. Under these conditions it is the magma which now moves relatively to the crystals." In brief, when the magma is in excess of the crystals, it is the crystals that intrude (presumably through the overlying magma); when the crystals are in excess of the magma, it is the magma that intrudes. This is an example of the type of mechanics which Dr. Nockolds is obliged to employ in order to make crystal differentiation work.

Dr. Nockolds has written (1940, p. 501) : " The mode of intrusion of the almost pure subtractive types is extremely difficult to visualize. This difficulty is sometimes used as an argument against such rocks being crystal accumulations and against the hypothesis of crystallization-differentiation. The fact is usually overlooked that it is equally difficult to account for them in any other way." Dr. Nockolds ignores the fact that such rocks are very easily accounted for by the hypothesis that they represent the zone of fixation of the basic constituents, driven from the zones of granitization; that they are examples of the much ignored but all-important phenomenon-the basic front.

(8) It is unreasonable for Dr. Nockolds to suggest that the Loch Doon evidence was used in my letter as an argument against his conclusions when, in fact, none of that evidence had been given. Loch Doon was mentioned merely to indicate that an explanation other than that supported by Dr. Nockolds is possible, and thus to relieve the necessarily negative criticism which formed the main substance of my letter.

If, as Dr. Nockolds states, crystal differentiation " explains why rocks of more extreme acid character are not found here or in other igneous rock series ", what explanation is advanced for the origin of the quartz veins which certainly are found here?

"The facts brought forward in connection, more especially, with the light constituents indicate a most striking similarity of behaviour between these constituents in natural magmas and in experimentally determined melts. Is it an accident that the last residual liquids of 
natural magmas should lie on the ternary cotectic curve?" (my italics). Such remarks by Dr. Nockolds are excellent examples of Petitio Principii, a fallacy all too common in discussion on the plutonic rocks. We can study plutonic rocks, but we cannot study plutonic magmas. To maintain that a given plutonic rock originated from a magma is no more than a hypothesis, and as such requires evidence for its support. If the evidence favours a magmatic origin then the question of the origin of the magma arises. Supporters of the hypothesis of solid diffusion do not deny that there have been magmas; they trace the stages leading up to their origin. Dr. Nockolds evidently forgets that the " reasonable scientific hypothesis " that he supports is based on his choice of a parental magma.

Donald B. McInTyre.

Grant InSTITUTE OF Geology,

UNIVERSITY OF EDINBURGH. 10th February, 1947.

\section{AN ESTIMATE OF THE AGE OF THE EARTH}

SIR,-In his letter to the Geological Magazine (this volume, p. 57) Professor Kuenen expresses his belief that my recent estimate of the age of the earth refers not to the time of origin of the earth as a planet, but to the time of origin of "the materials forming the earth". I had not overlooked the fundamental distinction to which Professor Kuenen directs attention; this and many other points not yet discussed will be fully dealt with in a detailed paper that is now being prepared. Meanwhile, however, I must make it quite clear that what I have determined is the most probable age of the rock material containing that dispersed rock-lead from which-by localized concentration brought about during various metallogenic epochs-lead ores have been formed. Geological and geochemical data (and also the results of the investigation under discussion) all consistently indicate that the source of the lead ores is the sialic part of the continental crust ; or, in other words, that lead ores represent concentrations from the granitic layer and its sedimentary and metamorphic derivatives. Accordingly, the age I have determined refers to the time when the granitic layer separated from average earth material during the consolidation of the globe. It is generally considered to be highly probable that the earth was originally gaseous and that the period of consolidation, up to the time of formation of a solid crust, was relatively short. Jeffreys, for example, estimates that "the earth probably became solid within 15,000 years of its ejection from the sun ". Even if this estimate were wrong by a factor of a thousand, the age of the granitic layer would not be appreciably different from the age of the earth. 